\title{
BMJ Global Health Impact of a demand-side integrated WASH and nutrition community-based care group intervention on behavioural change: a randomised controlled trial in western Kenya
}

\author{
Matthew C Freeman (D) , ${ }^{1,2}$ Anna S Ellis, ${ }^{1}$ Emily Awino Ogutu, ${ }^{2}$ \\ Bethany A Caruso (D) ,2 Molly Linabarger, ${ }^{2}$ Katie Micek, ${ }^{1}$ Richard Muga, ${ }^{3}$ \\ Amy Webb Girard (D) , ${ }^{2}$ Breanna K Wodnik (D) , ${ }^{2}$ Kimberly Jacob Arriola (D) ${ }^{4}$
}

To cite: Freeman MC, Ellis AS, Ogutu EA, et al. Impact of a demand-side integrated WASH and nutrition community-based care group intervention on behavioural change: a randomised controlled trial in western Kenya. BMJ Global Health 2020;5:e002806. doi:10.1136/ bmjgh-2020-002806

Handling editor Soumitra S Bhuyan

- Additional material is published online only. To view please visit the journal online (http://dx.doi.org/10.1136/ bmjgh-2020-002806).

Received 1 May 2020 Revised 6 July 2020 Accepted 21 August 2020

Check for updates

C Author(s) (or their employer(s)) 2020. Re-use permitted under CC BY-NC. No commercial re-use. See rights and permissions. Published by BMJ.

For numbered affiliations see end of article.

Correspondence to Dr Matthew C Freeman; matthew.freeman@emory.edu

\section{ABSTRACT}

Introduction Growth shortfalls and diarrhoeal diseases remain a major cause of morbidity and mortality in low-income settings. Due to the multifaceted causes of undernutrition and the identified limitations of siloed nutrition programmes, improving the delivery of integrated water, sanitation, hygiene (WASH) and nutrition programming could improve child health.

Methods We conducted a cluster randomised trial in western Kenya to assess the impact on household behaviours of a novel, theory-informed and integrated WASH and nutrition intervention delivered through care groups as compared with the standard care group approach. We developed an intervention targeting practices relating to food hygiene, mealtime and feeding, and compound cleanliness, each using various behavioural change techniques to influence the uptake of targeted behaviours. Prespecified behavioural outcomes were verified through direct observation, 24 hours recall, and self-reported picture-based methods.

Results Compared with control households, a greater proportion of intervention households had a hygienic food preparation area (Risk double difference (RDD) 0.81, $95 \% \mathrm{Cl} 0.68$ to 0.96 ), had stored food hygienically (RDD $0.76,95 \% \mathrm{Cl} 0.58$ to 1.00 ), had a functional handwashing station (RDD $0.64,95 \% \mathrm{Cl} 0.56$ to 0.74 ), provided a safe space for their child to play (RDD $0.73,95 \% \mathrm{Cl} 0.56$ to 0.96 ), and who fed their children thickened porridge (RDD $0.56,95 \% \mathrm{Cl} 0.51$ to 0.63 ) at endline. The proportion of children 6-24 months in intervention households consuming a sufficient diversity of foods (RDD $0.81,95 \% \mathrm{Cl}$ 0.64 to 1.04 ) was higher than in control households; however, there was a non-significant increase in the percentage of pregnant and lactating women receiving an adequate diversity of foods in their diets (RDD $0.86,95 \% \mathrm{Cl}$ 0.70 to 1.05 ) among intervention compared with control households at endline.

Conclusion Our integrated WASH and nutrition intervention resulted in important changes in behaviours. This theory-informed intervention could be added to existing care group programmes to considerable advantage.

\section{Key questions}

What is already known?

- Dietary diversity, high nutrient food and reduced exposure to faecal pathogens are critical for child growth and development. Developing and scaling programmes to address growth shortfalls within the first 1000 days of life would substantially impact long-term health and development outcomes.

- Siloed approaches to improve nutrition and reduce enteric infections of pregnant and lactating mothers and infants have shown moderate success. However, there has been limited evidence that communitybased interventions can yield substantial gains in nutrition and enteric infection.

- Few integrated water, sanitation and hygiene (WASH) and nutritional interventions rely on behavioural theory for intervention development.

What are the new findings?

- Our integrated demand-side behavioural change intervention, developed as part of a multisectoral collaboration between researchers, development partners and community-based organisations, catalysed important changes in seven key WASH and nutritional behaviours relevant for the first 1000 days of life. The theory-informed approach was delivered through an at-scale care group delivery strategy.

\section{INTRODUCTION}

Stunting affects nearly one-fourth of children under 5 worldwide, and although the prevalence of stunting has recently declined, it remains a major public health concern, particularly in low-income and middleincome countries. ${ }^{1-3}$ Suboptimal growth during the first 2 years of life has been shown to increase risk of death from infectious disease in childhood. ${ }^{4}$ While the first 1000 


\section{Key questions}

What do the new findings imply?

- Our cluster randomised trial revealed considerable improvements in pre-defined behaviours by caregivers. Behavioural changes resulting from this intervention could result in significant improvement in child health; further research should be undertaken to determine if changes in behaviour translate to gains in child health. Commonly delivered knowledge-based intervention strategies should be complemented with other strategies informed by behavioural theory, formative research, and behavioural trials to optimise delivery and impact on behavioural change.

days of life from conception to 24 months is regarded as a critical window for the prevention of stunting, there is evidence that suggests the importance of maternal nutrition from preconception as well. ${ }^{5}$ Stunting can have irreversible negative effects on future health and development, including cognition, language, social-emotional functioning, and physical well-being ${ }^{7}$ which can lead to educational and financial achievement gaps in highly affected regions or countries. ${ }^{8}$ For these reasons, it is critical to normalise growth for pregnant women and children to ensure future health and well-being in highburden regions.

Improving the diets of young children can reduce stunting, though at best, only by about one-third. ${ }^{9}$ Improvements through nutrition are hindered by barriers related to food access and availability, and complications due to symptomatic or asymptomatic infections. ${ }^{710}$ Exposure to faecal pathogens, both human and animal, resulting in diarrhoeal disease or even persistent exposure resulting in asymptomatic infection-leading to environmental enteric dysfunction-are hypothesised as significant causes of growth faltering. ${ }^{311-13}$ Unsafe drinking water, poor sanitation access, and inadequate hygiene (WASH) increase that exposure.

Due to the multifaceted causes of undernutrition and the identified limitations of siloed nutrition programmes, multisectorial and integrated approaches are needed to address underlying determinants of malnutrition and child stunting. ${ }^{14} 15$ WASH improvements can reduce exposure to enteric pathogens; however, the impacts of WASH interventions have found mixed results on stunting and diarrhoea, ${ }^{16-20}$ which kills between $10 \%$ and $15 \%$ of children under 5 each year globally and is largely due to inadequate WASH. ${ }^{21} 22$ The links between specific pathogens and experiences of moderate to severe diarrhoea may be amplified by malnutrition. ${ }^{23}$ The mixed evidence of programme impact could be attributed to poor uptake or failure of the interventions to effectively disrupt all possible transmission routes, such as through animal faeces or food hygiene, ${ }^{24-26}$ and recommendations have been made to identify and implement strategies that radically reduce faecal contamination of the environment. $^{27}$
To better understand the potential for impact on reducing stunting through integrated WASH and nutrition programming, improved interventions are needed to address multiple routes of exposure. Knowledge-based interventions and health communication alone may only be minimally effective for improving child nutrition and WASH practices. ${ }^{1528}{ }^{29}$ Building on knowledge and health communication through behavioural skills may allow participants to transform practices into habit. And while several studies have shown that nutritional behavioural change interventions can have an impact on growth, it remains unclear what makes these interventions work, for whom and at what cost. ${ }^{30}$ Integrated interventions can address both suboptimal nutrition and poor WASHrelated behaviours, target the whole person and their social (ie, household and community members) and physical environment, and draw from relevant theories of behavioural change in order to develop the most effective, scalable approaches to combat stunting adaptable across myriad contexts. Addressing additional underlying social determinants that affect maternal and child nutrition and WASH behaviours-such as household food allocation and dietary diversity-are important. ${ }^{31}{ }^{32}$ Incorporating underlying social determinants of key behaviours acknowledge an individual's social (ie, family, religious community) and physical environment.

The Care Group approach-implementated by dozens of international non-governmental organisations to improve child health across many countries-is typified by a training cascade that incorporates training of community health workers and neighbour women groups (NWGs) that provide peer support to mothers to adopt healthy practices. ${ }^{33}$ This model has been successfully shown to impact undernutrition in Mozambique by $2.2 \%$ annually, as well as contribute to behavioural change improvements and substantial declines in under five mortality in several countries. ${ }^{34-37}$ In Bolivia, care group promotion of education and water filters led to $90 \%-97 \%$ of households using filters (from $0 \%$ ) and reduced diarrhoea by $14 \% .{ }^{38}$ However, additional rigorous evidence is needed on how to expand this approach to integrated programmes, and improve impact and operational efficiency.

The purpose of this study was to assess the impact of a novel, theory-informed, and integrated WASH and nutrition behavioural change intervention-named Chakruok Makare, 'Better Beginnings'. The intervention was developed through a multistage process that included theoryderived formative research, ${ }^{39}$ extensive review of the literature of effective intervention components, trials of improved practice (TIPs) and stakeholder engagement. ${ }^{40} \mathrm{~A}$ critical aspect of this intervention development was that it was designed to be scaled and delivered within the context of an established and commonly employed health delivery modality: the Care Group model. ${ }^{33}$ Our hypothesis was that our theory-informed integrated WASH and nutrition intervention would deliver changes 


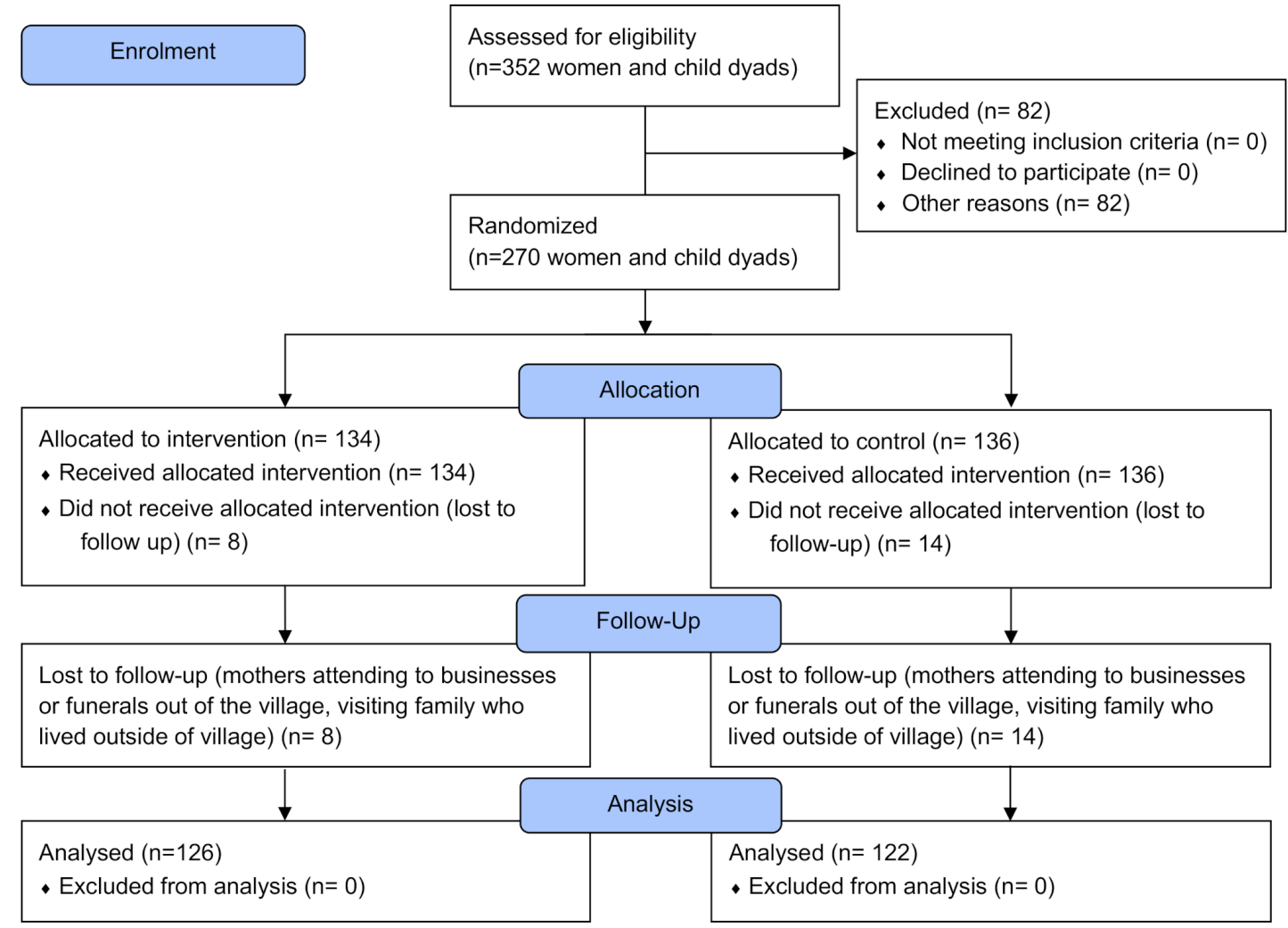

Figure 1 Consort flow diagram.

to behaviours above and beyond a standard care group approach.

\section{METHODS}

\section{Evaluation design and setting}

We conducted a cluster randomised trial among household members from 42 NWGs in Homa Bay and Migori Counties in western Kenya (figure 1), the catchment area of the parent THRIVE II programme, an early childhood development programme led by Catholic Relief Services (CRS) and local implementing partners. We assessed the impact of our intervention - Chakruok Makare-on WASH and nutrition behaviours above and beyond the care group approach currently delivered via standard THRIVE II programming. We collected survey data and structured spot-checks at baseline and endline to quantify the difference between behavioural outcomes in the intervention and control groups. We supplemented these data with qualitative data collection to explore the reasons for success of the intervention and/or challenges with delivery (to be published separately). The THRIVE II programme focused by design on geographic areas with high HIV/AIDS prevalence due to the vulnerability of children from these areas; Homa Bay has the highest adult HIV prevalence of any county (26\%) in Kenya; Migori's HIV prevalence was $15 \%$. $^{39}$

\section{Outcomes of interest}

Our primary outcomes of interest, preidentified through formative qualitative work, ${ }^{41}$ and their normative definitions are in table 1; more extensive definitions are included in online supplemental materials. We also assessed the households for WASH parameters and food insecurity based on the food insecurity access scale. ${ }^{42}$

\section{Intervention design}

We used several relevant methodological frameworks to design a set of integrated nutrition/WASH interventions in Kenya, as detailed in our intervention design approach published elsewhere. ${ }^{40}$ When evaluating complex interventions, it is important to identify the multiple causal pathways, levels of intervention, and feedback loops. ${ }^{43}$ We began by adapting key pieces from the Starr and Fornoff theory of change development model (2016) to identify the current problems, underlying causes of the problems, long-term changes needed and the activities required to achieve long-term change. We then adapted key steps from Michie's Behaviour Change Wheel ${ }^{44}$ to define the types of behavioural change that are expected to occur and what intervention functions would need to take place to produce the desired behavioural change. ${ }^{44}$ The final step was to test and modify the intervention strategies using an adapted TIPs approach, ${ }^{45}$ to determine which interventions and techniques to include in the scaled-up package of behavioural interventions.

Standard approach (control group): THRIVE II focused on teaching a series of key messages about WASH, infant and young child feeding, positive parenting, and early stimulation. Messaging was delivered through an adaptation of the Care Group model, 
Table 1 Primary outcomes

\begin{tabular}{|c|c|c|}
\hline Outcomes of interest & Operational definition & Verified through \\
\hline $\begin{array}{l}\text { 1. Hygienic food } \\
\text { preparation space }\end{array}$ & $\begin{array}{l}\text { A hygienic food preparation space will be defined as one which has all four } \\
\text { features: } \\
\text { Presence of a food preparation surface that is cleanable } \\
\text { Preparation area is not accessible by animals } \\
\text { Clean utensils } \\
\text { Stored in a space that is not accessible by animals } \\
\text { Stored in a dry space } \\
\text { Visibly free of dirt/debris } \\
\text { Handwashing station can be found within } 10 \mathrm{~m} \text { of the food preparation } \\
\text { space }\end{array}$ & Direct observation \\
\hline $\begin{array}{l}\text { 2. Hygienic food } \\
\text { storage }\end{array}$ & $\begin{array}{l}\text { Hygienic food storage will be defined as one which has all four features: } \\
\text { Food is not accessible by animals } \\
\text { Food is not accessible by young children } \\
\text { Food is covered } \\
\text { Food is free of flies }\end{array}$ & Direct observation \\
\hline $\begin{array}{l}\text { 4. Safe play } \\
\text { environment for } \\
\text { children } 6-24 \text { months } \\
\text { of age }\end{array}$ & $\begin{array}{l}\text { A safe play environment will be defined as one which has all four features: } \\
\text { Free of human faeces } \\
\text { Free of animal faeces } \\
\text { Free of garbage/household waste } \\
\text { Free of sharp objects and other potential harms }\end{array}$ & Direct observation \\
\hline $\begin{array}{l}\text { 5. Dietary diversity for } \\
\text { pregnant and lactating } \\
\text { women }\end{array}$ & $\begin{array}{l}\text { Sufficient dietary diversity for pregnant and lactating women will be defined } \\
\text { as having consumed food from five or more food groups. }\end{array}$ & $\begin{array}{l}24 \text { hours dietary } \\
\text { diversity recall }\end{array}$ \\
\hline
\end{tabular}

a community-based strategy for behavioural change ${ }^{46}$; the training and delivery cascade is depicted in figure 2. Community health volunteers (CHVs) were trained by the implementing organisation and in turn trained care groups that were composed of 10-15 care group volunteers (CGVs). CGVs were community women who were selected by their neighbour women to lead a neighbour women group (NWG). NWGs were composed of 6-15 women, to whom CGVs facilitated behavioural change through messaging and demonstration sessions they learnt in the care group setting. CGVs also followed up through home visits to encourage behavioural change based on the NWG sessions. Through THRIVE II, CGVs received an initial care group training which focused primarily on delivering basic health messaging with the assistance of a flipbook translated into the local language, Dholuo.

Chakruok Makare (intervention group): Our enhanced intervention used the same Care Group delivery modality, but focused on refining the messages and enhancing the delivery. We increased capacity building of CGVs and local CHVs, and increased supportive supervision to provide personalised feedback and support to participants through home visits. The intervention delivered a graduated bundle of three packages targeting practices relating to (1) food hygiene, (2) mealtime and feeding, and (3) compound cleanliness and sanitation. ${ }^{40}$ Neighbour women received messaging and peer support during NWGs. Derived from the THRIVE II behavioural change materials, each package used various behavioural change techniques to influence the uptake of targeted behaviours. ${ }^{44}$ Participants were also provided with minimal inputs to enable behavioural change, including information, education and communication materials (pledge cards, food hygiene card, dietary diversity tracking calendar, dietary diversity food wheel, clean compound storybook, feeding counseling card), and hardware (washbasin, pitcher and soap for handwashing stations, mesh food covers, demarcated bowl and spoon). ${ }^{47}$ There were two trainings to introduce 


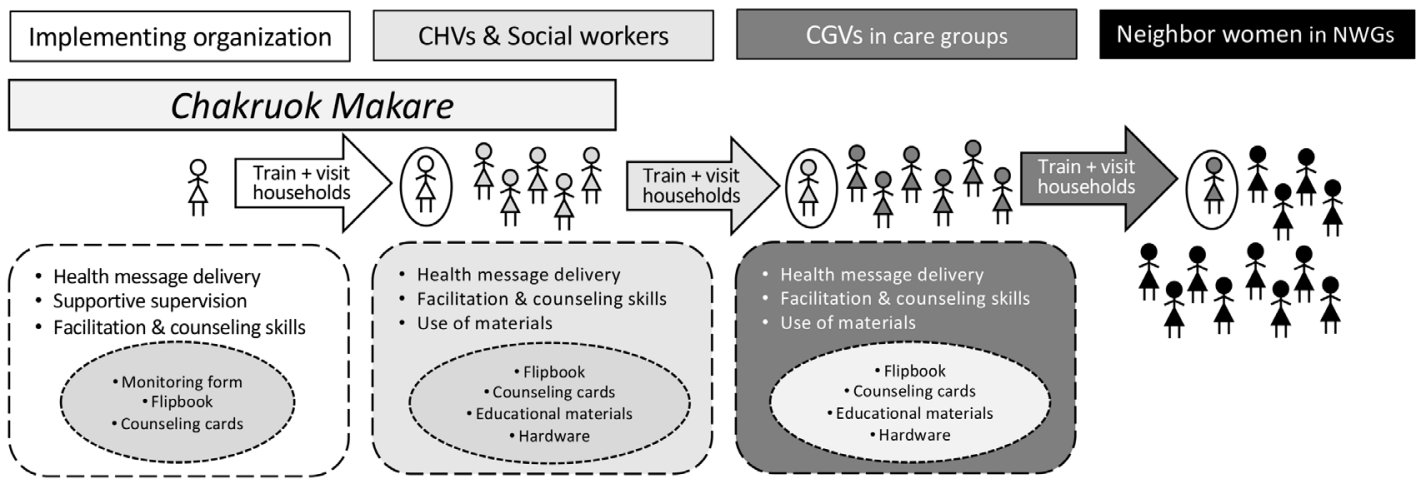

\section{Standard Care Group approach}

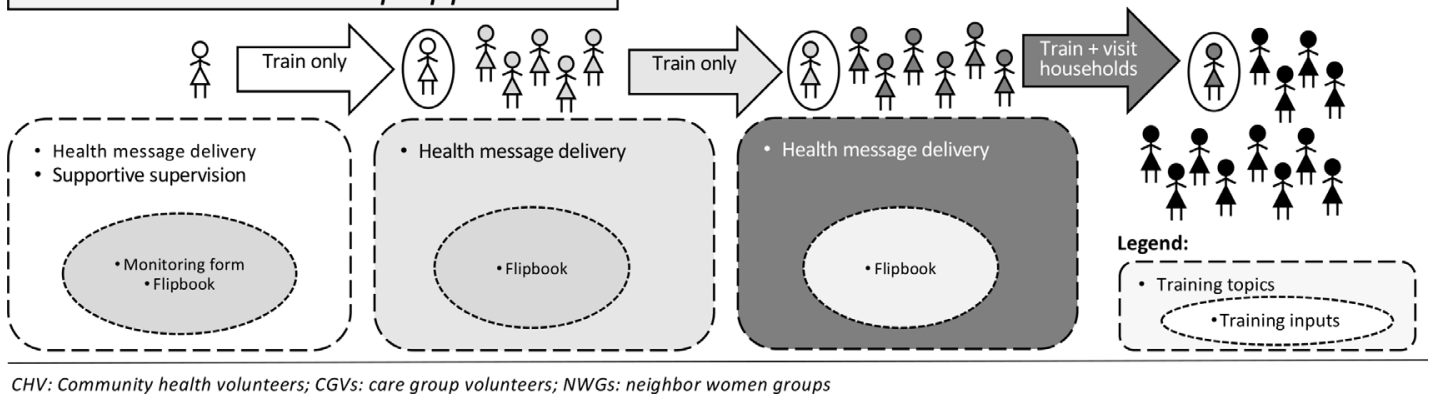

Figure 2 Comparison of Chakruok Makare intervention trainings with THRIVE II using additional components above and beyond the standard care group approach.

and validate the intervention: the first included implementing partners and CHVs, and was led and facilitated by project staff and case managers who had worked on TIPs; the second training included CGVs in addition to all participants from the first meeting. Trainings emphasised facilitation and counselling skills in addition to the messages; CHVs and social workers were trained on using monitoring forms adapted from THRIVE II that included measures on accurate delivery of messages in addition to facilitation skills. Overall, the interventions were delivered over 5 months. Additional detail on the behavioural techniques and approach to intervention development can be found elsewhere. ${ }^{40}$

During home visits and initial NWG meetings, CGVs and CHVs were accompanied by the case managers and occasionally by the social workers to provide supportive supervision. The social workers and the case managers recorded CGV delivery, accuracy of messages and support on monitoring forms, reviewing it with the CGV following their delivery. Two weeks after household visits, CHVs conducted random spot-checks in households to see how and if the interventions were being used and also address any barriers to intervention use. The social workers and the case managers also conducted random spotchecks. Figure 2 compares the THRIVE II and Chakruok Makare intervention trainings.

\section{Sample size and power calculations}

The sample size was calculated using OpenEpi V.3.01 using the preintervention prevalence of the main outcomes of interest from pilot data collected in sites adjacent to the study area. Of the seven primary outcomes, outcome 2-the presence of a hygienic food storage area $(30 \%$ in the pilot study) - produced the most conservative sample size. Based on that prevalence, we estimated a minimum sample size requirement of 138 mother-child dyads; the calculations account for 42 clusters averaging 7 women per cluster, so sample size was doubled to account for the design effect $(\mathrm{DEFF}=2)$ for a total sample size estimate of 276 . The evaluation is powered to detect a significant change of $25 \%$ in the risk difference of presence of a hygienic food storage area, using $80 \%$ power and $\alpha=0.05$. We anticipated that the project would continue to enrol new mothers into both arms of the study, but this did not happen towards the end of the study period, which ended up limiting our power for some outcomes reliant on pregnant and lactating women or children under 2 years (eg, outcomes 4-6).

\section{Household eligibility and recruitment}

NWGs were randomly selected from a full list of THRIVE II participating villages. Any NWG with eight or fewer women were excluded, as were a second NWG from the same community once one was selected. Mothers who were part of the remaining 42 NWGs ( $\mathrm{N}$ women=352) were eligible for inclusion if they met the following criteria: (1) were a member of a THRIVE II NWG, (2) were above the age of 18 , and (3) were not a CGV. While CGVs were part of the NWGs, they were excluded from the baseline and endline survey because they had received additional trainings and education beyond that of the other non-CGV neighbour women.

\section{Randomisation}

We conducted a 1:1 stratified random allocation (by county) of the NWGs to the Chakruok Makare 
intervention or to act as a comparison using a random number generator. Both groups received the standard care group intervention (figure 2). Following allocation, we compared the arms based on prespecified criteria: (1) Number of women with children under the age of 2; (2) Number of women currently pregnant; (3) Number of women currently lactating; and (4) Number of women who had completed any schooling beyond primary school (grade 8). If the groups were not within $2 \mathrm{SD}$ of each other in any of the four above-mentioned variables, the randomisation process was repeated. This was done to ensure balance given the small number of clusters. The process was completed 14 times in Homa Bay and 9 times in Migori.

\section{Data collection and management}

Women participating in the study NWGs were interviewed by the research teams using a structured survey to collect baseline data. This included all women who were found at home after two attempts and consented. Baseline data collection took place from June to July 2017 and endline data collection took place from May to June 2018, 2 weeks after the intervention was completed, by a team of four trained enumerators. Direct observations were conducted during unannounced visits by trained enumerators. Data were entered directly into Android TECNO phones; all data were collected in Open Data Kit (ODK) (opendatakit.org). All completed surveys were uploaded to a secure server using ODK Aggregate and device memories were cleared each day. Data were stored in a password-protected file in a secured cloudbased server. Given the nature of the intervention, it was not possible to blind data collectors or participants to the intervention allocation.

\section{Data analysis}

Primary and secondary outcome measures were compared between intervention and comparison mothers at endline to assess the effectiveness of the intervention, controlling for baseline values as an 'intentionto-treat' analysis and adjusting for village clustering. We calculated the risk double differences (RDD) for primary outcomes using generalised estimating equations. Given the relatively small numbers of clusters, we conducted randomisation inference as a robustness check on the findings. Data were cleaned and analysed in Stata V.15.

\section{Public involvement}

Community-based organisations and the County Ministries of Health were involved in the development and dissemination of the intervention and were provided feedback on results.

\section{RESULTS}

We conducted the baseline survey in 270 households and 42 NWGs (134 intervention, 136 control) from June-July 2017. The mean number of women surveyed per NWG was 6.4 (SD 1.7). At endline, we conducted the survey in 248 households (126 intervention, 122 control) in 39 NWGs from May-June 2018 (mean 6.5, SD 4.5). During the intervention, three NWGs were lost due to participant attrition. Participants were lost at follow-up due to migration, attrition, and work outside of the village.

\section{Demographics, WASH and food insecurity}

General demographic information of the mothers are presented in table 2. Fewer mothers had children under 2 at the endline, in both intervention and control groups, as children aged out and recruitment was not ongoing beyond the baseline. The study population had poor access to safe and sufficient quantities of water, as demonstrated by the high number of households using surface water as the main source of drinking water at baseline and endline, and by the number of households that must travel at least $30 \mathrm{~min}$ to collect drinking water (table 2). Sanitation access was also limited among this population, with less than half (44\%) having access to a functional latrine.

Food insecurity was experienced by most households in the study sample, and we did not find an impact of our three measures of food insecurity as a result of the intervention. We found a secular decrease households that experienced anxiety and uncertainty about the food supply in the last 30 days. There were also slight decreases in the percentage of households who reported insufficient quality of food supply in the last 30 days, and in intervention households who reported insufficient food intake and its consequences in the last 30 days (table 3 ).

\section{Primary outcomes}

The primary outcomes for households in each study arm at baseline and endline are shown in table 4, with quantification of additional constituent behaviours in online supplemental tables S1-S6. The intervention increased the proportion of households with a hygienic food preparation area by $21 \%$ points (RDD $21 \%, 95 \%$ CI $4 \%$ to $39 \%$ ), those that hygienically store food by $27 \%$ points (RDD $27 \%, 95 \%$ CI $0 \%$ to $59 \%$ ), those with a functional handwashing station by $44 \%$ points (RDD $44 \%$, 95\% CI $30 \%$ to $58 \%$ ), and those with a safe play space by $31 \%$ points (RDD $31 \%, 95 \%$ CI $37 \%$ to $58 \%$ ). Our intervention led to improvements in dietary diversity for pregnant and lactating women (RDD 15\%, 95\% CI $-5 \%$ to $35 \%$ ) and for children (RDD 21\%, 95\% CI $-4 \%$ to $45 \%$ ). Only three households fed their children appropriately thickened porridge at baseline; the intervention led to a $57 \%$ point increase in that indicator (RDD 57\%, 95\% CI 47\% to $68 \%)$. No adverse effects on participants were reported as a result of this study. Our randomisation inference analysis did not reveal any substantive deviations in the results across all outcomes of interest.

\section{DISCUSSION}

We developed and tested a novel, evidence-based, theory-informed integrated WASH and nutrition intervention within the context of an existing Care Group 
Table 2 Descriptive statistics of the study sample at baseline and endline

\begin{tabular}{|c|c|c|c|c|}
\hline \multirow[b]{2}{*}{ Study population characteristics } & \multicolumn{2}{|l|}{ Baseline } & \multicolumn{2}{|l|}{ Endline } \\
\hline & $\begin{array}{l}\text { Intervention } \\
\mathrm{N}=134, \%\end{array}$ & $\begin{array}{l}\text { Control } \\
\mathrm{N}=136, \%\end{array}$ & $\begin{array}{l}\text { Intervention } \\
\mathrm{N}=126, \%\end{array}$ & $\begin{array}{l}\text { Control } \\
\mathrm{N}=122, \%\end{array}$ \\
\hline Has a child under the age of $2^{*}$ & $85(64)$ & $85(63)$ & $69(52)$ & $63(52)$ \\
\hline Currently lactating* & $66(49)$ & $66(49)$ & $55(44)$ & $50(41)$ \\
\hline Currently pregnant* & $15(11)$ & $16(12)$ & $13(10)$ & $7(6)$ \\
\hline $\begin{array}{l}\text { Completion of any schooling beyond primary school } \\
\text { (eighth grade)* }\end{array}$ & $23(17)$ & $24(18)$ & $27(21)$ & $18(15)$ \\
\hline Currently married & $117(87)$ & $122(90)$ & $116(92)$ & $106(87)$ \\
\hline \multicolumn{5}{|l|}{ Surface water as main source } \\
\hline For drinking water & $68(51)$ & $70(52)$ & $69(55)$ & $57(47)$ \\
\hline For cooking & $89(66)$ & $108(80)$ & $88(70)$ & $82(67)$ \\
\hline For cleaning & $91(70)$ & $111(82)$ & $92(73)$ & $85(70)$ \\
\hline $\begin{array}{l}\text { Travel time to and from main source of drinking water is } \\
30+\min \end{array}$ & $98(73)$ & $111(82)$ & $80(64)$ & $93(76)$ \\
\hline Household access to a functional latrine & $61(46)$ & $59(43)$ & $53(42)$ & $55(45)$ \\
\hline $\begin{array}{l}\text { Participants who reported open defecating at last time of } \\
\text { defecation }\end{array}$ & $39(29)$ & $54(40)$ & $38(30)$ & $39(32)$ \\
\hline $\begin{array}{l}\text { Participants who reported child aged 0-24 months } \\
\text { defecating on ground at last time of defecation } †\end{array}$ & 45 (53) & $43(51)$ & $30(44)$ & 27 (44) \\
\hline $\begin{array}{l}\text { Participants who reported disposing of child (6-24 } \\
\text { months) faeces in an unsafe place (field, water source, } \\
\text { etc) } \ddagger\end{array}$ & 21 (34) & $29(41)$ & $21(30)$ & 19 (32) \\
\hline
\end{tabular}

${ }^{*}$ Characteristic used to assess balance between study arms.

†Denominator based on the number of households with a child under the age of 2 at the time of the survey.

$\ddagger$ Denominator based on the number of households with a child between the ages of 6 and 24 months at the time of survey.

delivery modality in western Kenya. ${ }^{40}$ Our intervention was successful at achieving substantial increases in these outcomes above and beyond the standard care group approach, the results of which can be inferred by the secular trends in the control group. These are considerable improvements with important programmatic and public health significance.
Our intervention resulted in substantial improvements in hygienic food preparation areas (outcome 1) and safe storage of food (outcome 2). Though food is one of the most critical pathways for children to be exposed to faecal pathogens, ${ }^{48}$ food hygiene interventions are underemphasised in WASH and nutrition programming, and few studies have measured the impact of any

Table 3 Food insecurity at baseline and endline

\begin{tabular}{|c|c|c|c|c|c|}
\hline \multirow[b]{2}{*}{ Food Insecurity } & \multicolumn{2}{|l|}{ Baseline } & \multicolumn{2}{|l|}{ Endline } & \multirow[b]{2}{*}{$\begin{array}{l}\text { Risk double difference, } \\
(95 \% \mathrm{Cl}){ }^{*}\end{array}$} \\
\hline & $\begin{array}{l}\text { Intervention } \\
\mathrm{N}=134, \%\end{array}$ & $\begin{array}{l}\text { Control } \\
\mathrm{N}=136, \%\end{array}$ & $\begin{array}{l}\text { Intervention } \\
\mathbf{N}=126, \%\end{array}$ & $\begin{array}{l}\text { Control } \\
\mathrm{N}=122, \%\end{array}$ & \\
\hline $\begin{array}{l}\text { Households who reported insufficient quality } \\
\text { of food supply in last } 30 \text { days }\end{array}$ & $120(90)$ & $129(95)$ & $104(83)$ & 114 (93) & $-5 \%(-17 \%$ to $6 \%)$ \\
\hline $\begin{array}{l}\text { Households who reported insufficient food } \\
\text { intake and its physical consequences in last } \\
30 \text { days }\end{array}$ & $120(90)$ & 127 (93) & 102 (81) & $110(90)$ & $-6 \%(-18 \%$ to $7 \%)$ \\
\hline
\end{tabular}

${ }^{*}$ Risk double difference calculated using generalised estimating equations is the difference between treatment arms at endline, controlling for baseline values, adjusting for village-level clustering.

†Reported results reflect household responses to occurrence questions only and do not reflect the proscribed Household Food Insecurity Access frequency-of-occurance component. Consequently, these results may differ from other reports in this region. ${ }^{42}$ 
Table 4 The impact of the intervention on primary behavioural outcomes

\begin{tabular}{|c|c|c|c|c|c|}
\hline \multirow[b]{2}{*}{ Primary outcomes } & \multicolumn{2}{|c|}{ Baseline } & \multicolumn{2}{|c|}{ Endline } & \multirow{2}{*}{$\begin{array}{l}\text { Risk double } \\
\text { difference \%, } \\
(95 \% \mathrm{Cl})^{*}\end{array}$} \\
\hline & $\begin{array}{l}\text { Int. } \\
\mathrm{N}=134\end{array}$ & $\begin{array}{l}\text { Control } \\
\mathbf{N}=133\end{array}$ & $\begin{array}{l}\text { Int. } \\
\mathrm{N}=126\end{array}$ & $\begin{array}{l}\text { Control } \\
\mathbf{N}=121\end{array}$ & \\
\hline 1. Households with hygienic food prep area & $5(4)$ & $3(2)$ & $45(36)$ & $12(10)$ & 21 (4 to 39$)$ \\
\hline 2. Households who store food hygienically & $13(34)$ & $17(52)$ & $22(43)$ & $14(34)$ & $27(0$ to 55$)$ \\
\hline $\begin{array}{l}\text { 3. Households with a functional handwashing } \\
\text { station }\end{array}$ & $4(3)$ & $12(9)$ & $44(40)$ & $0(0)$ & $44(30$ to 58$)$ \\
\hline $\begin{array}{l}\text { 4. Households with a safe play environment } \\
\text { for children } 6-24 \text { months of age }\end{array}$ & $15(24)$ & $23(32)$ & $40(69)$ & $24(47)$ & $31(37$ to 58$)$ \\
\hline $\begin{array}{l}\text { 5. Pregant and lactating women who } \\
\text { consumed } 5+\text { food groups in previous } \\
24 \text { hours }\end{array}$ & $22(27)$ & $17(21)$ & $34(52)$ & $17(32)$ & $15(-5$ to 35$)$ \\
\hline $\begin{array}{l}\text { 6. Children } 6-24 \text { months who consumed } 4+ \\
\text { food groups in previous } 24 \text { hours }\end{array}$ & $20(30)$ & $23(32)$ & $32(55)$ & $19(37)$ & $21(-4$ to 45$)$ \\
\hline 7. Caretaker fed thickened porridge to child & $1(2)$ & $2(3)$ & $82(68)$ & $14(12)$ & 57 (47 to 68$)$ \\
\hline
\end{tabular}

*Risk double difference calculated using generalised estimating equations is the difference between treatment arms at endline, controlling for baseline values, accounting for community-level clustering.

intervention on increasing hygienic food storage. ${ }^{49}$ Food hygiene presented a contextual challenge related to the larger sociocultural realities of caretakers. ${ }^{50}$ In addition, different high-risk foods require different food hygiene strategies; for example, if milk is the primary vector for food-related pathogens, ${ }^{51}$ it would require a different type of hazard mitigation than porridge. One main way to protect food is to cover it while cooling to avoid contact with vectors, such as flies. We provided a low-cost, locally fabricated mesh food cover. Despite reported use, this cover was not always used in intervention households; covering food may be dependent on what food is cooked and continued beliefs/knowledge on food spoilage. Even with the improvements to these outcomes, utensil storage often remained accessible to animals (mostly chickens), so there was still the potential for contamination through poultry contact.

We observed a substantial increase in the presence of water and soap together within 10 metres of a food preparation area (outcome 3). Handwashing programmes can reduce the risk of diarrhoea by $30 \%$, based on a metaanalysis of 33 studies. ${ }^{22}$ However, many do not achieve large changes in handwashing practices. Our study showed commensurate changes to handwashing to the WASH-benefits efficacy trial in Kenya (where the intervention was highly intensive); handwashing increased by $65 \%$ in year 1 , but dropped to $11 \%$ in year $2 .{ }^{19}$ In Zimbabwe, the SHINE study also achieved similar levels of handwashing behavioural change (30\%) to our study. Self-reported handwashing is known to be highly biased and unreliable, sometimes estimated at $10 \% .^{22}$ As such, we relied on presence of a handwashing station, a recognised proxy for handwashing. ${ }^{22}$

In our study, we saw a substantial improvement in observable measures relating to safe play spaces by reducing exposure to child and animal faeces, as well as other solid waste (outcome 4). Children's hands are often contaminated by their environment, and frequent mouthing and soil-eating behaviours can lead to enteropathogen exposure and infection. ${ }^{52-54}$ Prior to the intervention, many beneficiary household members did not believe or recognise that child faeces could have negative impacts on child health, ${ }^{40}$ similar to work elsewhere. ${ }^{55}$ Additionally, while people acknowledged that some animal faeces could have negative health impacts, respondents did not believe that cow faeces were harmful or as harmful to human health. People had a difficult time accepting this message because they used cow dung mixed with mud as plaster for their homes. The changes reported in disposal of child and animal faeces may show a shift caused by knowledge from messaging that was emphasised in training. There has been recent attention to safe play spaces to reduce young children's exposure to faecal pathogens in the environment, either from animals or humans. However, the SHINE trial found no such impact of play spaces on child growth or diarrhoea ${ }^{56}$ There are few other studies that have rigorously assessed behavioural change related to safe play spaces, ${ }^{57}$ and efforts to reduce childhood exposure through interventions with greater fidelity may still be useful. We did not focus on prefabricated spaces; our outcome was related to maintenance, including cleaning of an existing location in the compound.

Caretakers that disposed of child faeces in an unsafe area (open field, stream, etc) did not significantly decrease over the intervention timeframe, potentially showing an ongoing challenge for households that did not have a functional latrine to dispose of child faeces safely. Our intervention was strictly demand-side in nature at individual household level, so for households with an existing latrine, we promoted latrine use and safe disposal of child and animal faeces. For those households without a latrine, we did not target construction of latrines but promoted burial of child and animal faeces. Burial is not 
considered 'safe' disposal of faeces according to WHO/ UNICEF Joint Monitoring Programme, but we believed it was important to provide some guidance on improved practices in the absence of latrines in the households. ${ }^{58}$ Because of the challenges and greater time commitment to cleaning up animal faeces during the rainy season, future interventions should take seasonality into better consideration when advising tools for faeces cleanup.

The difference in diet diversity of pregnant and lactating women between intervention and comparison groups was considerable, but not statistically significant (outcome 5); given that children aged out of the cohort, we may have been underpowered to detect this difference. It is also possible that social desirability bias confounded our diet diversity results, however, we used an open recall method with nonleading probes to avoid leading participants to socially desired responses. Also, given both groups received education on diet diversity, it is unlikely that social desirability bias, if present, differed between the two groups. Research to identify effective social and behavioural change communication strategies to improve maternal diet quality lag behind research on complementary feeding. Pregnant and lactating women in intervention households increased their intake of vitamin A rich fruits and vegetables; other fruits and vegetables; legumes, beans and seeds; meats and fish; and milk and milk products. We used cues to action, goal setting and self monitoring as mechanisms for changes to behaviour. A 2014 systematic review by the SPRING group noted that social behavioural change communication (SBCC) strategies improved maternal intakes of key micronutrient rich foods such as dark green leafy vegetables and meats/fish, though degree of change differed by context and indicator assessed. ${ }^{59}$ Our findings for changes in meat/fish intakes were similar to changes observed in a behavioural change intervention in Senegal ${ }^{60}$ but less than those observed in a study in Egypt. ${ }^{61}$ Interventions included in this review used interpersonal counselling as the primary platform for SBCC with some also including community-based group approaches or mass media. ${ }^{62}$ In Burkina Faso ${ }^{63}$ and western Kenya, ${ }^{64}$ integrated agriculture and nutrition education interventions employing group-based and interpersonal counselling increased maternal dietary diversity but to a lesser extent than our study.

Our point estimate revealed a clinically relevant increase in dietary diversity of children age 6-24 months $(21 \%)$; we may have been underpowered to stastically confirm this difference due to our index children ageing out by endline (outcome 6). This finding is comparable to interventions in India and China that focused on social and behavioural change communication without other nutrition supports. ${ }^{6566}$ A care group study in Mozambique that revealed an $8.1 \%$ decline in undernutrition showed changes in dietary diversity of between $21 \%$ and $28 \% .^{34}$

We substantially increased porridge thickness (outcome 7), an important determinant of energy density adequacy yet rarely assessed in complementary feeding interventions. In formative research, we found fear of small children choking on thick porridge to be a key barrier to correct practice. The introduction of a slotted spoon and dosing bowl provided useful guidance to mothers on appropriate porridge thickness, and demonstrations of children eating thickened porridgebuilt confidence that children would not choke. The delivery of a simple technology, alongside demonstrations, illustrated the importance of applied trainings over knowledge-based strategies alone.

\section{Strengths and limitations}

We conducted rigorous formative research to determine barriers and drivers to the behaviours we were aiming to change, and conducted a modified TIPs approach to determine which interventions would be most acceptable and behaviours attainable. ${ }^{40}$ We applied behavioural change theory to inform and complement how our intervention could promote behavioural change. ${ }^{40}$ In addition, we conducted a process evaluation following the framework of Saunders $e t a b^{67}$ to determine areas for improvement to the standard THRIVE II intervention that we could incorporate into Chakruok Makare. Our process evaluation found that delivery of messages could be improved through additional training of CGVs and CHVs, more interactive meetings (ie, personal pledge setting), and a reduction in the number of messages (data not published). We trained CGVs to emphasise the benefits and the risks related to behaviour, which caretakers attributed to their shifts in behaviour. The process evaluation also highlighted the importance of increased monitoring, which was addressed by the addition of case works.

One major limitation of the study is that three of our seven indicators were self-reported, including foods fed to children, foods eaten by caretakers and porridge thickness. Since intervention households received extensive messaging on all of these indicators, it is possible that caretakers over-reported behaviours due to courtesy bias. Specifically, the extensive food recall conducted by enumerators required that respondents recall everything they had eaten throughout the day, resulting in recall bias. Another limitation is that the length of the intervention was 5 months, not long enough to show sustained behavioural change. Finally, we did not collect data related to health outcomes, such as the standard height and weight measures used to determine growth shortfalls and prevalence of diarrhoea. Respondents, including caretakers and CHVs, reported that fewer children were being seen at the health facilities for diarrhoea, and mothers reported that children seemed to be gaining more weight, but this information is anecdotal.

\section{CONCLUSIONS}

Care Group programmes have a well-documented evidence base in reducing undernutrition and under 5 
mortality, ${ }^{37} 68$ but few programmes have demonstrated changes to WASH and nutritional behaviours and outcomes. Our theory-informed and evidence-based intervention that integrated WASH and nutrition behaviours resulted in important changes in behaviours above and beyond an ongoing care group approach. We demonstrated an ability to identify and account for elements related to limited resources, seasonality, gender dynamics and other social conditions that were likely to affect the rollout of the intervention. Important enhancements included increased capacity building and supportive supervision of CGVs, a reduced number of messages per package, simplified messages for easy understanding, an emphasis on the consequences of key practices, the use of materials that stayed in the home and served as cues to action, and low-cost hardware to facilitate practices of food storage and porridge thickness measurement. Findings from Burundi indicated that it is feasible to transfer the delivery of an integrated care group approach from project staff to Ministry of Health officials with substantial cost savings. ${ }^{69}$ We believe that the findings of our study warrant testing and replication of these intervention tools in other contexts. This integrated, evidencebased intervention could be added to existing Care Group programmes to considerable advantage, though more research is needed to understand the sustainability and cost-effectiveness of the approach.

\section{Author affiliations \\ ${ }^{1}$ Gangarosa Department of Environmental Health, Emory University, Atlanta, Georgia, USA \\ ${ }^{2}$ Hubert Department of Global Health, Emory University, Atlanta, Georgia, USA ${ }^{3}$ Faculty of Health Sciences, Uzima University, Kisumu, Kenya \\ ${ }^{4}$ Department of Behavioral, Social, and Health Education Sciences, Emory University, Atlanta, Georgia, USA}

Twitter Bethany A Caruso @Caruso_Bethany and Breanna K Wodnik @BreannaWodnik

Acknowledgements Vanessa Tobin developed an initial scoping document that outlines synergies between WASH and nutrition and supported early stages of the project as the Chief of WASH for CRS. Catholic Relief Services: Maureen Kapiyo, David Leege, Elena McEwan, Fidelis Muthoni, Raphael Ofware, George Okoth; Emory University: Maryann Delea, Ellah Kadera, Alysse Kowalski, Sandra Gomez Ventura; Homa Hills Community Development Organization: Dennis Ochieng, Evelyne Otieno, Stephan Owino; Mercy Orphans: Tobias Ogaga, Josephine Okomo, Phenny Ogweno, Judith Wara; Uzima University: Dorothy Adhiambo, Lydia Atetwe, Lily Lukorito, Nicanor Muga, Jacqueline Okumu, Fredrick Okumu, Rosebel Ouda, Nancy Oyugi. We wish to thank the community members who spent their valuable time as part of the study.

Contributors MCF conceived of the study; MCF, AE, BAC, EO, RM, KJA, AWG designed the study; $\mathrm{EO}, \mathrm{AE}, \mathrm{RM}$ managed data collection with $\mathrm{BKW}, \mathrm{KM}$, and $\mathrm{ML}$; MCF, KM, ML, and BKW conducted data analysis; MCF wrote the first draft; All authors reviewed and provided edits.

Funding Catholic Relief Services was the main implementing partner and funded the study.

Competing interests None declared.

Patient consent for publication Not required.

Ethics approval This study was approved by the Emory University Institutional Review Board (Atlanta, GA USA) (\#IRB00090057), as well the National Commission for Science, Technology and Innovation (NACOSTI) and the Great Lakes University of Kisumu Ethical Review Boards in Kenya.

Provenance and peer review Not commissioned; externally peer reviewed.
Data availability statement Data are available in a public, open access repository. All relevant data and corresponding code will be uploaded for open access once paper is accepted.https://osf.io/mpk4n/

Supplemental material This content has been supplied by the author(s). It has not been vetted by BMJ Publishing Group Limited (BMJ) and may not have been peer-reviewed. Any opinions or recommendations discussed are solely those of the author(s) and are not endorsed by BMJ. BMJ disclaims all liability and responsibility arising from any reliance placed on the content. Where the content includes any translated material, BMJ does not warrant the accuracy and reliability of the translations (including but not limited to local regulations, clinical guidelines, terminology, drug names and drug dosages), and is not responsible for any error and/or omissions arising from translation and adaptation or otherwise.

Open access This is an open access article distributed in accordance with the Creative Commons Attribution Non Commercial (CC BY-NC 4.0) license, which permits others to distribute, remix, adapt, build upon this work non-commercially, and license their derivative works on different terms, provided the original work is properly cited, appropriate credit is given, any changes made indicated, and the use is non-commercial. See: http://creativecommons.org/licenses/by-nc/4.0/.

\section{ORCID iDs}

Matthew C Freeman http://orcid.org/0000-0002-1517-2572

Bethany A Caruso http://orcid.org/0000-0001-9738-9857

Amy Webb Girard http://orcid.org/0000-0003-4414-720X

Breanna K Wodnik http://orcid.org/0000-0003-1304-0194

Kimberly Jacob Arriola http://orcid.org/0000-0003-4568-0225

\section{REFERENCES}

1 Adair LS, Fall CHD, Osmond C, et al. Associations of linear growth and relative weight gain during early life with adult health and human capital in countries of low and middle income: findings from five birth cohort studies. Lancet 2013;382:525-34.

2 Black RE, Victora CG, Walker SP, et al. Maternal and child undernutrition and overweight in low-income and middle-income countries. Lancet 2013;382:427-51.

3 Ngure FM, Humphrey JH, Mbuya MNN, et al. Formative research on hygiene behaviors and geophagy among infants and young children and implications of exposure to fecal bacteria. Am J Trop Med Hyg 2013;89:709-16.

4 Caulfield LE, de Onis M, Blössner M, et al. Undernutrition as an underlying cause of child deaths associated with diarrhea, pneumonia, malaria, and measles. Am J Clin Nutr 2004;80:193-8.

5 Bhutta ZA, Das JK, Rizvi A, et al. Evidence-Based interventions for improvement of maternal and child nutrition: what can be done and at what cost? Lancet 2013;382:452-77.

6 Özaltin E, Hill K, Subramanian SV. Association of maternal stature with offspring mortality, underweight, and stunting in low- to middleincome countries. JAMA 2010;303:1507-16.

7 Walker SP, Wachs TD, Gardner JM, et al. Child development: risk factors for adverse outcomes in developing countries. Lancet 2007;369:145-57.

8 Van Rie A, Dow A, Mupuala A, et al. Neurodevelopmental trajectory of HIV-infected children accessing care in Kinshasa, Democratic Republic of Congo. J Acquir Immune Defic Syndr 2009;52:636-42.

9 Victora CG, Adair L, Fall C, et al. Maternal and child undernutrition: consequences for adult health and human capital. Lancet 2008;371:340-57.

10 Cumming O, Cairncross S. Can water, sanitation and hygiene help eliminate stunting? Current evidence and policy implications. Matern Child Nutr 2016;12 Suppl 1:91-105

11 Humphrey $\mathrm{JH}$. Child undernutrition, tropical enteropathy, toilets, and handwashing. Lancet 2009;374:1032-5.

12 Lin A, Arnold BF, Afreen S, et al. Household environmental conditions are associated with enteropathy and impaired growth in rural Bangladesh. Am J Trop Med Hyg 2013;89:130-7.

13 Zambrano LD, Levy K, Menezes NP, et al. Human diarrhea infections associated with domestic animal husbandry: a systematic review and meta-analysis. Trans $R$ Soc Trop Med Hyg 2014;108:313-25.

14 Casanovas MdelC, Lutter CK, Mangasaryan N, et al. Multi-sectoral interventions for healthy growth. Matern Child Nutr 2013;9 Suppl 2:46-57.

15 Ruel MT. Measuring infant and young child complementary feeding practices: indicators, current practice, and research gaps. Nestle Nutr Inst Workshop Ser 2017;87:73-87.

16 Clasen T, Pruss-Ustun A, Mathers CD, et al. Estimating the impact of unsafe water, sanitation and hygiene on the global burden of 
disease: evolving and alternative methods. Trop Med Int Health 2014;19:884-93.

17 Humphrey JH, Mbuya MNN, Ntozini R, et al. Independent and combined effects of improved water, sanitation, and hygiene, and improved complementary feeding, on child stunting and anaemia in rural Zimbabwe: a cluster-randomised trial. Lancet Glob Health 2019;7:e132-47.

18 Luby SP, Rahman M, Arnold BF, et al. Effects of water quality, sanitation, handwashing, and nutritional interventions on diarrhoea and child growth in rural Bangladesh: a cluster randomised controlled trial. Lancet Glob Health 2018;6:e302-15.

19 Null C, Stewart CP, Pickering AJ, et al. Effects of water quality, sanitation, handwashing, and nutritional interventions on diarrhoea and child growth in rural Kenya: a cluster-randomised controlled trial. Lancet Glob Health 2018;6:e316-29.

20 Pickering AJ, Arnold BF, Dentz $\mathrm{H}$, et al. Usage of Carbon-Financed ("Lifestraw") Water Filters by Rural Kenyan Households. American Journal of Tropical Medicine and Hygiene 2015;93:174-5.

21 Liu L, Oza S, Hogan D, et al. Global, regional, and national causes of child mortality in 2000-13, with projections to inform post-2015 priorities: an updated systematic analysis. The Lancet 2015:385:430-40.

22 Wolf J, Hunter PR, Freeman MC, et al. Impact of drinking water, sanitation and handwashing with soap on childhood diarrhoeal disease: updated meta-analysis and meta-regression. Trop Med Int Health 2018;23:508-25.

23 Tickell KD, Sharmin R, Deichsel EL, et al. The effect of acute malnutrition on enteric pathogens, moderate-to-severe diarrhoea, and associated mortality in the global enteric multicenter study cohort: a post-hoc analysis. Lancet Glob Health 2020;8:e215-24.

24 Freeman MC, Garn JV, Sclar GD, et al. The impact of sanitation on infectious disease and nutritional status: a systematic review and meta-analysis. Int J Hyg Environ Health 2017;220:928-49.

25 Pickering AJ, Null C, Winch PJ, et al. The WASH benefits and SHINE trials: interpretation of WASH intervention effects on linear growth and diarrhoea. Lancet Glob Health 2019;7:e1139-46.

26 Penakalapati G, Swarthout J, Delahoy MJ, et al. Exposure to animal feces and human health: a systematic review and proposed research priorities. Environ Sci Technol 2017;51:11537-52.

27 Cumming O, Arnold BF, Ban R, et al. The implications of three major new trials for the effect of water, sanitation and hygiene on childhood diarrhea and stunting: a consensus statement. BMC Med 2019;17:1-9

28 Aboud FE, Singla DR. Challenges to changing health behaviours in developing countries: a critical overview. Soc Sci Med 2012;75:589-94.

29 Bergeron K, Abdi S, DeCorby K, et al. Theories, models and frameworks used in capacity building interventions relevant to public health: a systematic review. BMC Public Health 2017;17:914.

30 Fabrizio CS, van Liere M, Pelto G. Identifying determinants of effective complementary feeding behaviour change interventions in developing countries. Matern Child Nutr 2014;10:575-92.

31 Aubel J. The role and influence of grandmothers on child nutrition: culturally designated advisors and caregivers. Matern Child Nutr 2012;8:19-35.

32 Pelto GH, Armar-Klemesu M. Identifying interventions to help rural Kenyan mothers cope with food insecurity: results of a focused ethnographic study. Matern Child Nutr 2015;11 Suppl 3:21-38.

33 Care groups: implications of current innovations, scale-up and research. summary report of a technical Advisory group meeting 2014.

34 Davis TP, Wetzel C, Hernandez Avilan E, et al. Reducing child global undernutrition at scale in Sofala Province, Mozambique, using care group volunteers to communicate health messages to mothers. Glob Health Sci Pract 2013;1:35-51.

35 Edward A, Ernst P, Taylor C, et al. Examining the evidence of underfive mortality reduction in a community-based programme in Gaza, Mozambique. Trans R Soc Trop Med Hyg 2007;101:814-22.

36 Perry H, Sivan O, Bowman G, et al. Averting childhood deaths in resource-constrained settings through engagement with the community: an example from Cambodia. In: Essentials of community health. Sudbury, MA: Jones and Bartlett, 2010: 169-74.

37 George CM, Vignola E, Ricca J, et al. Evaluation of the effectiveness of care groups in expanding population coverage of key child survival interventions and reducing under- 5 mortality: a comparative analysis using the lives saved tool (list). BMC Public Health 2015; $15: 835$

38 Lindquist ED, George CM, Perin J, et al. A cluster randomized controlled trial to reduce childhood diarrhea using hollow fiber water filter and/or hygiene-sanitation educational interventions. Am J Trop Med Hyg 2014;91:190-7.
39 KNBS. Kenya demographic and health survey; 2014

40 Jacob Arriola KR, Ellis A, Webb-Girard A, et al. Designing integrated interventions to improve nutrition and wash behaviors in Kenya. Pilot Feasibility Stud 2020;6:10.

41 Ellis A, McClintic EE, Awino EO, et al. Practices and perspectives on Latrine use, child feces disposal, and clean play environments in Western Kenya. Am J Trop Med Hyg 2020;102:1094-103.

42 Coates J, Swindale A, Bilinsky P. Household food insecurity access scale (HFIAS) for measurement of food access: indicator guide: version 32007.

43 De Silva MJ, Breuer E, Lee L, et al. Theory of change: a theorydriven approach to enhance the medical Research Council's framework for complex interventions. Trials 2014;15:267.

44 Michie S, van Stralen MM, West R. The behaviour change wheel: a new method for characterising and designing behaviour change interventions. Implement Sci 2011;6:42.

45 Manoff Group. Trials of improved practices (TIPs): giving participants a voice in program design. Washington, DC The Manoff Group; 2005.

46 Hanold M, Wetzel C, Davis T. Care groups: a training manual for program design and implementation. Washington, DC Technical and Operational Performance Support Program; 2014.

$47 \mathrm{Kram} \mathrm{N}$, Melgen S, Kedera E, et al. The acceptability of dietary tools to improve maternal and child nutrition in Western Kenya. Public Health Nutr 2016;19:1823-33.

48 Wang Y, Moe CL, Null C, et al. Multipathway quantitative assessment of exposure to fecal contamination for young children in low-income urban environments in Accra, Ghana: the SaniPath analytical approach. Am J Trop Med Hyg 2017;97:1009-19.

49 Mumma J, Simiyu S, Aseyo E, et al. The safe start trial to assess the effect of an infant hygiene intervention on enteric infections and diarrhoea in low-income informal neighbourhoods of Kisumu, Kenya: a study protocol for a cluster randomized controlled trial. BMC Infect Dis 2019;19:1-11.

50 Mumma JAO, Cumming O, Simiyu S, et al. Infant food hygiene and childcare practices in context: findings from an urban informal settlement in Kenya. Am J Trop Med Hyg 2020;102:220-2.

51 Tsai K, Simiyu S, Mumma J, et al. Enteric pathogen diversity in infant foods in low-income neighborhoods of Kisumu, Kenya. Int $J$ Environ Res Public Health 2019;16:506.

52 Kwong LH, Ercumen A, Pickering AJ, et al. Age-Related changes to environmental exposure: variation in the frequency that young children place hands and objects in their mouths. J Expo Sci Environ Epidemiol 2020;30:205-16.

53 Parvez SM, Azad R, Pickering AJ, et al. Microbiological contamination of young children's hands in rural Bangladesh: Associations with child age and observed hand cleanliness as proxy. PLoS One 2019;14:e0222355.

54 Davis E, Cumming O, Aseyo R, et al. Oral contact events and caregiver hand hygiene: implications for fecal-oral exposure to enteric pathogens among infants 3-9 months living in informal, peri-urban communities in Kisumu, Kenya. Int $J$ Environ Res Public Health 2018;15:192.

55 Majorin F, Freeman MC, Barnard S, et al. Child feces disposal practices in rural Orissa: a cross sectional study. PLoS One 2014;9:e89551.

56 Humphrey $\mathrm{JH}$. The impact of WASH and IYCF on stunting and anemia 2017

57 Ngure FM, Reid BM, Humphrey JH, et al. Water, sanitation, and hygiene (WASH), environmental enteropathy, nutrition, and early child development: making the links. Ann N Y Acad Sci 2014:1308:118-28.

58 WHO/UNICEF. Core questions on drinking-water and sanitation for household surveys. New York WHO/UNICEF Joint Monitoring Program for Water Supply and Sanitation; 2008.

59 Rennie W, Koniz-Booher P, Rogers B. SBCC in the Sahel: a landscape assessment of nutrition and hygiene social and behavior change communication in niger and Burkina Faso. Arlingtaon, VA USAID/Strengthening Partnerships, Results, and Innovations in Nutrition Globally (SPRING) Project; 2014.

60 Kung'U JK, Ndiaye B, Ndedda C, et al. Design and implementation of a health systems strengthening approach to improve health and nutrition of pregnant women and newborns in Ethiopia, Kenya, Niger, and Senegal. Matern Child Nutr 2018;14 Suppl 1:e12533.

61 Ahrari M, Houser RF, Yassin S, et al. A positive deviance-based antenatal nutrition project improves birth-weight in Upper Egypt. $J$ Health Popul Nutr 2006;24:498-507.

62 Lamstein S, Stillman T, Koniz-Booher P, et al. Evidence of effective approaches to social and behavior change communication for preventing and reducing stunting and anemia: findings from a systematic literature review 2014. 
63 Olney DK, Bliznashka L, Pedehombga A, et al. A 2-year integrated agriculture and nutrition program targeted to mothers of young children in Burkina Faso reduces underweight among mothers and increases their empowerment: a cluster-randomized controlled trial. J Nutr 2016;146:1109-17.

64 Girard AW, Grant F, Watkinson M, et al. Promotion of orange-fleshed sweet potato increased vitamin A intakes and reduced the odds of low retinol-binding protein among postpartum Kenyan women. $J$ Nutr 2017; 147:955-63.

65 Kilaru A, Griffiths PL, Ganapathy S, et al. Community-Based nutrition education for improving infant growth in rural Karnataka. Indian Pediatr 2005;42:425.

66 Sun J, Dai Y, Zhang S, et al. Implementation of a programme to market a complementary food supplement (Ying Yang Bao) and impacts on anaemia and feeding practices in Shanxi, China. Matern Child Nutr 2011;7 Suppl 3:96-111.
67 Saunders RP, Evans MH, Joshi P. Developing a process-evaluation plan for assessing health promotion program implementation: a how-to guide. Health Promot Pract 2005;6:134-47.

68 Perry H, Morrow M, Davis T, et al. Care groups II: a summary of the child survival outcomes achieved using volunteer community health workers in resource-constrained settings. Glob Health Sci Pract 2015;3:370-81.

69 Weiss J, Makonnen R, Sula D. Testing the effectivenes and sustainability of an integrated care group model as compared to a traditional care group model. Final report. New York Concern Worldwide; 2013.

70 Kennedy G, Ballard T, Dop MC. Guidelines for measuring household and individual dietary diversity Food and Agriculture Organization of the United Nations; 2011.

71 World Health Organization. Indicators for assessing infant and young child feeding practices: Part 2: measurement; 2010. 